\title{
A study examining the association between body image, self esteem and identity in the context of the undergraduate college students in Mumbai
}

\author{
Meghna Basu Thakur ${ }^{1}$, Ayesha Charles ${ }^{2}$ \\ ${ }^{1}$ Head and Assistant Professor, ${ }^{2}$ Assistant Professor-C.H.B \\ Department of Psychology, R.D. National College, Bandra (Mumbai) \\ Corresponding author: Ms. Meghna Basu Thakur \\ Email-meghnabasuthakur@yahoo.com
}

\begin{abstract}
The current study is an attempt to examine whether there exists an association between body image, selfesteem and identity. The Scales employed to examine this association are the Aspects of Identity Questionnaire (AIQ-IV), Body Image Questionnaire (BIQ) and the State Self Esteem Scale (SSES). The BIQ entails answering questions related to physical attributes, focusing on features or attributes the person is conscious of or would like to change and the extent to which this interferes with their interpersonal interactions and relationships. The State Self Esteem Scale measures self-esteem along 3 dimensions namely performance self-esteem, social self-esteem and appearance self-esteem. The AIQ-IV measures different aspects of Identity such as Personal Identity, Social, Relational and Collective Identity respectively. The Scales were administered to a sample of 50 undergraduate students of R.D. National College, Bandra from the ages 18-21 years. The data gleaned was analysed using inferential statistics such as Pearson's R and multiple correlation. The data gleaned was analysed using Pearson's Product Moment Correlation as an inferential statistic or Pearson's r. Individualistic cultures stress on the need for competition, competence and independence. Thus, self enhancement and competition would be crucial aspects. Body image is closely linked to self enhancement and thus individualistic cultures are likely to lay a greater emphasis on physical appearance and social image. On the other hand, the Indian culture as the Asian cultures are more collectivistic in nature. Thus, the emphasis or the pressures to maintain a certain body image as in the Western culture may not be as pertinent.
\end{abstract}

Keywords: Self-image, Mental health, Physiological appearance, Relationships, College students, India.

(Paper received $-29^{\text {th }}$ December 2017 , Peer review completed $-6^{\text {th }}$ January 2018)

(Accepted $-9^{\text {th }}$ January 2018)

\section{INTRODUCTION}

Body Image is defined as a person's self-feeling, perception and satisfaction about his/her own body that involves his/her physical look, facial appearance, and other bodily features like height and weight. An individual's satisfaction with their physiological self is closely linked to sense of self or identity, their selfesteem and their interpersonal interactions within a sociocultural milieu. The sense of self encompasses feelings of self-worth in conjunction with the beliefs one holds in relation to the self. This is why identity is integral to understanding the way a person thinks and feels about themselves. As per research findings selfesteem and body image are more intricately intertwined for females versus males.

In a study done on first year undergraduate U.S. female students, to examine the role of gender in the association between body image and self-esteem it was found that gender plays a role in body dissatisfaction and self-esteem and that female college students are more concerned with body image while 
male college students are more concerned with muscularity versus body shape or weight per se. Females experience greater pressure and dissatisfaction due to the social pressure to be thin. In comparison the research with respect to men body image and self-esteem is limited. In terms of men, self-esteem is contingent on the ability to adhere to the masculine cultural concept in terms of body appearance. Thus, body image in terms of masculinity is associated with muscularity versus body weight. This includes a more athletic physical appearance. Muscularity is positively associated with self-esteem in men and thinness is positively associated with self-esteem in women due to the prevalent gender role stereotypes. The male and female self-concept therefore is closely linked with physical appearance [1].

In a study done on University students on Social phobia as a mediating factor in the relation between selfesteem and body image it was found that individuals with social phobia have more negative self-image which expands to their assessment of their physical self. This in turn hampers with their ability to form close interpersonal and social relationships. The tendency to evaluate oneself negatively in light of physical appearance is linked to the cultural attitude of 'beauty bias'. As per the findings of social experiments this bias operates in most social and cultural situations. A person who is physically attractive is judged positively in terms of other unrelated traits such as intelligence, competence and other social skills. This is linked to the irrational belief 'what is beautiful is good' [1]. The tendency to evaluate oneself unfavourably in light of physical attractiveness has been propagated largely by the media. The media creates pressure to conform to the ideal masculine or feminine appearance for both boys and girls [2].

Another important mediating factor in the link between body image and self-esteem is the type of culture an individual belongs to that is collectivist or individualistic. The Asian and Indian cultures are generally identified as collectivist while the Western culture is identified as individualistic. In a study done on attitudes towards gender roles, self-esteem and body image on 202 Korean college women, 52 Singaporean college women, 171 African-American college women, and 109 Caucasian-American college women it was found that the relationship between body image and self-esteem was mediated by attitudes towards gender roles. In other words, there existed a positive relationship between physical appearance and selfesteem in traditional women but not in non-traditional women. Thus, the significance attached to physical appearance and body image and the attention given to it was contingent on attitudes towards gender role stereotypes. This is due to the assumption that traditional femininity is linked with concern with physical appearance and beauty. However, fitness and health are a cultural attribute. Another important finding was with respect to identification with in group and type of culture that is individualistic vs collectivist. As per the findings African women who identified more strongly with theirs in group did not adhere to or pay attention to the dominant perceptions about physical appearance. However contradictory results were found with respect to Korean college students who belong to a collectivist culture. An individualistic culture emphasizes on social comparison, competition and independence. Korean women were observed to engage in high levels of self enhancement as cosmetic surgery was sought after. This suggests a need for self-improvement and engaging in social comparison which is contrary to the attitude of a collectivist culture [4-6].

The above literature is restricted to the Western socio-cultural context with little work on the association between body image, self-esteem and identity among Indian college students. The current study is an attempt to remedy this gap.

\section{METHODOLOGY}

\section{Sample Characteristics}

The sample population consisted of undergraduate college students between the ages 18 to 21 years in Mumbai. The sample selected for the research study was 50 undergraduate college students from R.D. National College, Bandra, Mumbai between the ages 18 to 21 years.

\section{Measures}

The aim of the experiment was to examine the association between the three variables of interest namely body image, self-esteem and identity in the context of undergraduate college students in Mumbai. For this reason, three scales were administered to a sample of 50 college students both male and female. The Scales 
employed to examine this association are the Aspects of Identity Questionnaire (AIQ-IV), Body Image Questionnaire (BIQ) and the State Self Esteem Scale (SSES).

- The Body Image Questionnaire [7] entails answering questions related to physical attributes, focusing on features or attributes the person is conscious of or would like to change and the extent to which this interferes with their social, behavioural and interpersonal interactions indicated through 8-point and 4-point rating scales respectively.

- The State Self Esteem Scale, [8] a 20-item scale that measures a participant's self-esteem at a given point in time. The 20 items are subdivided into 3 components of self-esteem: (1) performance selfesteem, social self- esteem, and appearance self-esteem. All items are answered using a 5-point scale $(1=$ not at all, $2=$ a little bit, $3=$ somewhat, $4=$ very much, $5=$ extremely $)$

- The AIQ-IV $[9,10]$ a 45-item scale that measures different aspects of the participants Identity such as Personal Identity, Social, Relational and Collective Identity respectively, using a 5- point Likert Scale (1= Not important to my sense of who I am, 2= Slightly important to my sense of who I am, 3= Somewhat important to my sense of who I am, $4=$ Very important to my sense of who I am and $5=$ Extremely important to my sense of who I am)

\section{Procedure}

The three Scales for the study that is the Body Image Questionnaire, The Aspects of Identity Questionnaire and the State Self Esteem Scale were distributed among 50 undergraduate college students in R.D. National College. The students were explained each of the Scales and given instructions on how to fill them. The students were also told not to reveal any personal details such as their name or roll.no. as all the data collected was strictly for research purposes and highly confidential. The students handed over the Scales one by one and on completion of the three Scales were thanked for their participation in the research study.

\section{RESULTS AND DISCUSSION}

The data gleaned was analysed using Pearson's Product Moment Correlation as an inferential statistic or Pearson's $\mathrm{r}$. The aim of the study was to examine the association between the three variables of interest that is Body Image, Self-esteem and identity. Since the aim was to examine an association Pearson's $r$ was the inferential statistic employed for the purpose. The sample consisted of 50 college undergraduate students in the urban Indian context. The data from the 50 undergraduate students were collected on the basis of these three scales for each of the 3 variables namely, body image, identity and self-esteem. The three variables body image, self-esteem and identity were correlated using Pearson's $\mathrm{r}$ and multiple correlation. Pearson's product moment correlation was applied to the variables body image and identity. With reference to Table 1 and the Fig. 1 which is the graphical representation of the scores on the three variables of interest, the correlation coefficient between the two variables body image and identity was 0.0911 . The correlation coefficient derived for the next two variables namely identity and self-esteem was 0.1738 and the correlation coefficient for the final 2 variables body image and self-esteem was 0.0630 .

The range for interpretation of correlation spans from 0 indicating no correlation to + or -1 indicating a perfect positive or negative correlation respectively.

Table 1 - Correlation between Body Image, Self esteem and Identity in relation to the three measures

\begin{tabular}{|l|c|c|c|}
\hline & Body Image & Identity & Self Esteem \\
\hline BODY IMAGE & --- & 0.091 & 0.063 \\
\hline IDENTITY & --- & --- & 0.173 \\
\hline SELF ESTEEM & 0.063 & 0.173 & --- \\
\hline
\end{tabular}


Figure 1

Graphical representation of Scores of 50 undergraduate students on the three variables Body Image, Self Esteem and Identity

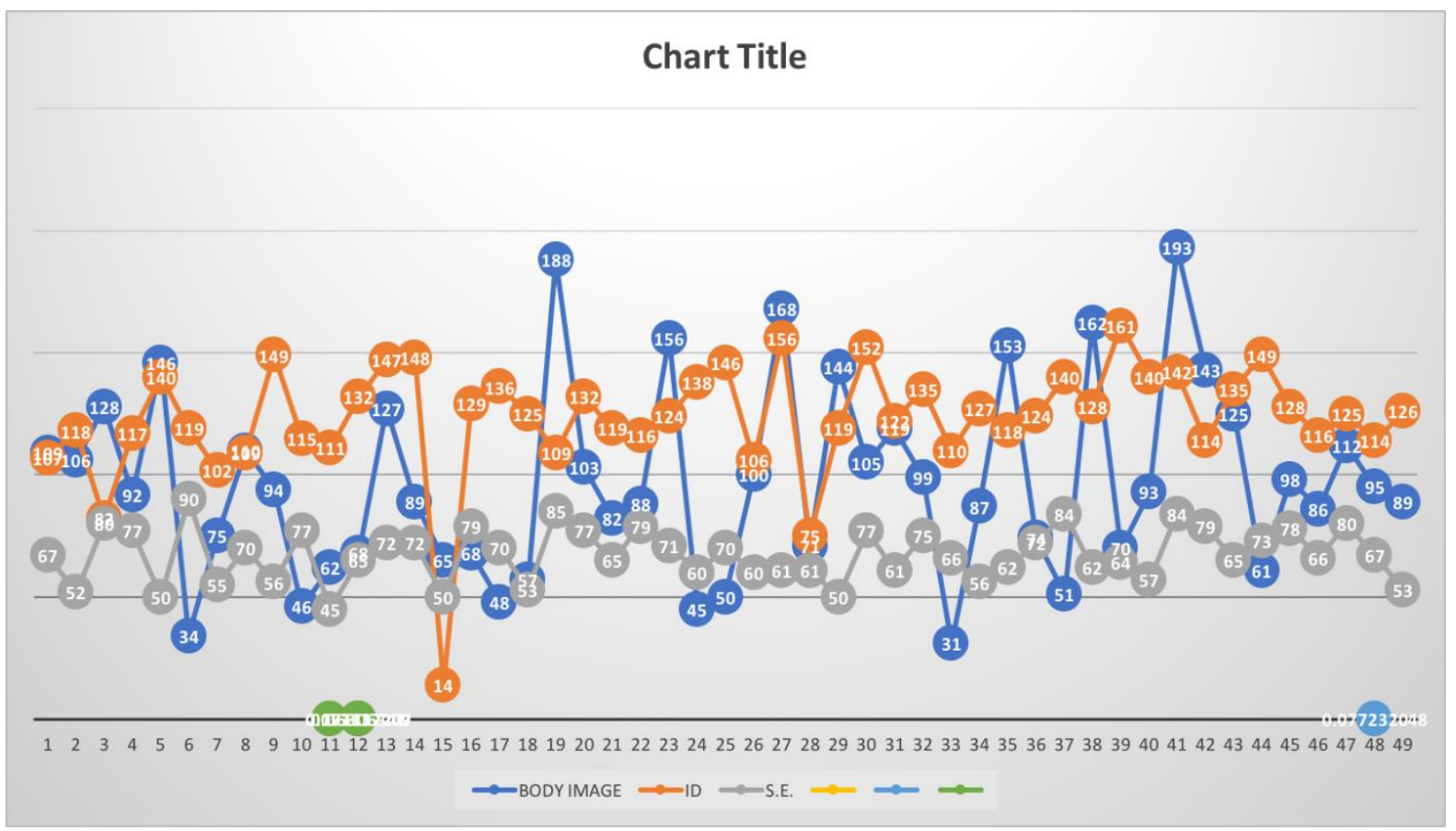

In terms of the correlation coefficients derived from the research study data the correlation coefficients between body image and identity, identity and self-esteem and body image and self-esteem were all very weak correlation. In other words, the correlation of 0.09 between body image and identity that there is very low correlation or almost no association between the 2 variables. Similar results were found for selfesteem and identity and body image and self-esteem. Thus, the study failed to find any significant associations between each of the variables of interest.

The values derived through the multiple correlation were as follows. With reference to Table 2 derived $\mathrm{r}$ value was 0.01 . the adjusted $r$ square value was 0.0001 , the adjusted $R$ square value was -1.04 . The significance of the multiple $\mathrm{R}$ square value was 0.02 . As per the table value the obtained $\mathrm{R}$ square value which is 0.02 was lower than the table value of $\mathrm{r} d f(3,47)$. Thus, the obtained $\mathrm{r} 2$ value or the multiple correlation coefficient was found to be insignificant at 0.05 levels of significance. Therefore, we accept the Null Hypothesis that there is no association or correlation between the variables body image, self-esteem, identity. The results of the study are thus not aligned with the findings of previous research studies which state that there exists a significant association between body image, self-esteem and identity.

The reason for the results of the study can be attributed to certain factors related to sample characteristics and socio-cultural influences. The sample consisted primarily of undergraduate college students between the ages 18-21 years from National College, Bandra. The lack of heterogeneity with respect to the sample may have led to a weak correlation between the 3 variables. The more homogeneous the sample the less the variance which would result in a correlation coefficient of a lesser magnitude.

A second explanation would be in relation to the type of culture. The Indian culture is more collectivistic as opposed to individualistic in nature. Individualistic cultures stress on the need for competition, competence and independence [11-13]. Thus, self enhancement and competition would be crucial aspects. Body image is closely linked to self enhancement and thus individualistic cultures are likely to lay a greater emphasis on physical appearance and social image. On the other hand, the Indian culture as the Asian cultures are more collectivistic in nature. Thus, the emphasis or the pressures to maintain a certain body image as in the Western culture may not be as pertinent. 


\section{REFERENCES}

1. Izgiç F, Akyüz G, Doğan O, Kuğu N. Social phobia among university students and its relation to self-esteem and body image. Can J Psychiatry 2004;49(9):630-4.

2. Polce-Lynch M, Myers BJ, Kliewer W, Kilmartin C. Adolescent self-esteem and gender: Exploring relations to sexual harassment, body image, media influence, and emotional expression. J Youth Adolesc 2001;30(2):225-44.

3. Lennon SJ, Rudd NA, Sloan B, Kim JS. Attitudes toward gender roles, self-esteem, and body image: Application of a model. Cloth Textiles Res J 1999;17(4):191-202.

4. Clay D, Vignoles VL, Dittmar H. Body image and self- esteem among adolescent girls: Testing the influence of sociocultural factors. J Res Adolesc 2005;15(4):451-77.

5. Lowery SE, Kurpius SE, Befort C, Blanks EH, Sollenberger S, Nicpon MF, Huser L. Body image, selfesteem, and health-related behaviors among male and female first year college students. J College Stud Dev 2005;46(6):612-23.

6. Tiggemann M. Body dissatisfaction and adolescent self-esteem: Prospective findings. Body Image 2005;2(2):129-35.

7. Veale D, Gournay K, Dryden W, Boocock A, Shah F, Willson R, Walburn J. Body dysmorphic disorder: a cognitive behavioural model and pilot randomised controlled trial. Behav Res Ther 1996;34(9):717-29.

8. Heatherton TF, Polivy J. Development and validation of a scale for measuring state self-esteem. J Personal Soc Psychol 1991;60(6):895.

9. Cheek JM, Tropp LR, Chen LC, Underwood MK. Identity orientations: Personal, social, and collective aspects of identity. In $102^{\text {nd }}$ Annual Convention of the American Psychological Association, Los Angeles 1994.

10. Cheek JM, Smith SM, Tropp LR. Relational identity orientation: A fourth scale for the AIQ. In Meeting of the Society for Personality and Social Psychology, Savannah, GA 2002.

11. McCaulay M, Mintz L, Glenn AA. Body image, self-esteem, and depression-proneness: Closing the gender gap. Sex Roles 1988;18(7-8):381-91.

12. Grossbard JR, Lee CM, Neighbors C, Larimer ME. Body image concerns and contingent self-esteem in male and female college students. Sex Roles 2009;60(3-4):198-207.

13. Ogden JE, Evans C. The problem of weighing: effects on body image, self esteem and mood. Int J Obesity 1996;20:272-7.

$* * * * * * * * * * * * * * * * * *$

$$
\begin{gathered}
\text { Acknowledgements - Nil } \\
\text { Conflict of Interest - Nil } \\
\text { Funding - Nil }
\end{gathered}
$$

